American Journal of Applied Sciences 8 (6): 617-627, 2011

ISSN 1546-9239

(C) 2011 Science Publications

\title{
Predictor Factors of Telecentres Outcome from the Users Perspectives in Rural Communities
}

\author{
${ }^{1}$ Mohammad Badsar, ${ }^{1}$ Bahaman Abu Samah, ${ }^{2}$ Musa Abu Hassan, \\ ${ }^{2}$ Nizam Bin Osman and ${ }^{1}$ Hayrol Azril Mohd Shaffri \\ Institute for Social Science Studies, \\ ${ }^{2}$ Department of Communication, \\ Faculty of Modern Languages and Communication, \\ University Putra Malaysia, 43400 Serdang, Selangor, Malaysia
}

\begin{abstract}
Problem statement: Information and Communication Technologies (ICTs) in developing countries is considered as a fundamental strategy of community development. In this regard, the government of Malaysia and developing agencies considered telecentres as a tool for providing the potential and benefits of ICTs for rural and remote community in order to make value and offer equal ICT access to all Malaysians and to transform Malaysia into a value based Knowledge Society by the year 2020. However, the lack of success and sustainability is a common problem for telecentre projects that cause increasing necessity for paying more consideration to extract lessons learned of projects, with particular attention to factors influence telecentre outcomes which is the aim of this study. Approach: the main purpose of this study was to define the predictor factors of telecentres outcomes from user's perception in rural communities in Malaysia. A cross sectional survey method was employed in the study and data were collected from 360 respondents who were randomly selected from the Pusat Internet Desa (PID) and Medan InfoDesa (MID) centers. For the purpose of analysis, Structural Equation Modeling (SEM) by AMOS software was used. Result: The results of the Structural Equation Modeling (SEM) analyses show that individual characteristics, telecentres characteristics, information characteristics and leadership competency variables had significant contribution toward the prediction of telecentre outcome. Also the results showed that the information characteristic variable had better contribution toward the prediction of telecentre outcomes in rural community. Conclusion: based on highest contribution of the information characteristics among investigated factors, it could be concluded that any efforts must be made to improve service quality and provide relevant content to respondent needs in local language. Thus, access to local and relevant content can play a critical role in stimulating the users in rural community to have a continuous connection with telecentres and finally achieving desire outcome.
\end{abstract}

Key words: Information characteristics, telecentres outcome, rural community, leadership competency

\section{INTRODUCTION}

Rural areas are frequently considered as information-poor and providing information has always been a central factor of rural development (Slaymaker, 2002). Access to information provides an opportunity to foster greater competitiveness, new economic growth and job creation, better access to basic services, improved health and education outcomes and greater empowerment of rural communities (Rahman and Pathan, 2010). ICT can increase rural productivity and ICT awareness can greatly contribute to sustainable rural development in the developing countries (Rahman, M.U. Mahfuz, K.M. Ahmed and R.M.A.P. Rajatheva, 2005) one of the ICT project which is Telecentres. Telecentres is "a physical space that provides public access to ICTs for educational, personal, social and economic development" (Gómez et al., 1999).

Now we are standing on a step where deploying ICT to bridge the 'digital divide' need to be seriously and genuinely addressed in order to fight poverty (Iskandarani, 2008) in developing countries (Ali and Bailur, 2007). Malaysia also has accepted ICT as key

Corresponding Author: Bahaman Abu Samah, Laboratory of Rural Advancement and Agriculture Extension, Institute for Social Science Studies, University Putra Malaysia 
Am. J. Applied Sci., 8 (6): 617-627, 2011

enablers of national development in order to achieve entirely developed nation by 2020 (Harris, Yogeesvaran and Lee, 2007; Samah, Shaffril, Hassan and D'Silva, 2011 ) and has been mobilizing efforts to reduce the digital divide among the people especially in the rural areas in Seventh, Eighth and Ninth Malaysian Plan (Supyan et al., 2009). Malaysian government has identified nine central strategic challenges towards its vision 2020 in which sixth of them arrive to establish a progressive and scientific society, a society that is forward looking and innovative and one that is not only a consumer of technology but also a contributor to technological and scientific civilization of the future (Musa and Hasim, 2008). To meeting these challenges, Malaysia has come out with a number of strategies such as National Information Technology Center, Universal Services Provider (USP), Pusat Internet Desa (PID) and Medan InfoDesa (MID) centers to strengthen and encourage ICT usage among the rural community (Samah, et al., 2011) and several ministries and also private initiatives has put aside a big amount of investment to adopt Malaysian citizen for technological contribution via the setting up of 1945 telecentres in all Malaysian states including Sabah and Sarawak (Norizan and Jalaluddin, 2008).

Despite of such an investment and effort many of these experiences have only partly reach to desire outcomes and very few of these projects have turn out to be sustainable (UNESCAP, 2006). It is the reason this study aim to investigate the predictor factors of Telecentres outcomes. Further this study look at the users' perspectives as Harris (2001) argued for importance and necessities of defining outcomes by the community users.

Outcomes are the result of adoption or rejection of an innovation such as Telecentres by an individual or a social system (Rogers, 2003). Harris (2001) proposed that achieving desire outcome such as individual empowerment and providing better economic condition should be related more closely to what a community need (aims) to attain, or could be motivated to attain, from its use of a telecentre. In this study consistent with Mancini and Marec (2004) and Harries (2001) models, telecentre outcomes defined and measured using three dimensions including (a) participant need met, (b) empowering individuals and (c) providing better economic condition.

There are different factors that found to predict the telecentres outcome by the researchers worldwide. But these factors mostly were identified through qualitative researches or conceptual models and there are no statistically proven factors and most importantly little are known about them in Malaysian context. Thus, this study using Harries (2001) conceptual framework investigated individual characteristics, telecentres characteristics, information characteristics and leadership competency.

In this study individual characteristics investigated in term of computer skills and innovativeness. New technologies such as ICT in telecentres often need new skills (Proenza et al., 2001) that its achievement depend on individual innovativeness (Lee, 2001). Successful development of such an characteristics result in achieving desire outcome (Mansell and Wahen, 1998). Telecentre characteristics investigated through; location of telecentres, telecentre network infrastructures and type and quality of services. Etta and Parvyn-Wamahiu (2003) in study of telecentres in Africa argued that inappropriate location is one important aspect, which directly affects access and use. Kumar and Best (2006) in study social impact and diffusion of telecentre use in rural India found that location of telecentres close to the residential localities are associated with attracting more users from those communities. Jusang et al. (2009) based on viewpoint of 60 ICT projects supervisors in rural areas of Malaysia revealed that success and failure of a ICT project more depends on increased equipment. Equipment and infrastructure should be selected cautiously to make sure it is suitable for the level and range of services to be supplied by the centre (Farr and Papandrea, 2004; 2006). Stable and functional infrastructure is a major section to facilitate the mission of a telecentre, which is substantial service provision (Jauernig, 2003). Zahurin et al. (2009) based on their study among the Malaysian telecentres indicated that a good delivery and quality services are very important aspects that contribute to telecentres' success.

Among information characteristics, the access to local and relevant content to community needs is of importance in predicting telecentre outcome. Inappropriate contents and materials would be useless to communities particularly if these contents are not delivered in national or local language (Nor Iadah et al., 2010). Best et al. (2009) argued that many telecentre projects have not realized the success as well as the prime objective because of many reason such as little or no local content. One of the chief challenges telecentres face is to provide suitable services and information for community members. To survive, telecentres must be considerably demand-driven and this translates into the need to supply people in the host communities with right of entry to helpful and relevant content (Colle, 2004). In addition to individual, telecentre and 
information characteristics, leadership competency are also is important in achieving desire telecentre outcome. Telecentre staff and management require to have a set of core competencies to efficiently direct telecentre operations to facilitate the success of its goals (Bailey, 2009).

\section{MATERIALS AND METHODS}

Population and sampling: The population of this study consist of the PID and MID telecentres' users in rural areas of Malaysia. The sample of the study was selected through multi-stage cluster sampling. In the first step, four states of Perak, Kedah, Terengganu and Johor were randomly selected representing central, northern, east coast and southern of Peninsular Malaysia, respectively. In the second step, within the selected states, telecentres were selected based on three criteria namely; being active, have enough experience means at least three years of activity and their users aged above 16. The cut-off point of the users' age was decided because based on pilot study which users below 16 years old experienced the difficulty to answer questionnaire. Finally the data were collected from 360 respondents (90 respondents per state) which were randomly selected from the 11 PID and 12 MID telecentres.

Measurement: The survey instrument comprises demographic information and five main constructs, namely individual characteristics, telecentre characteristics, information characteristics, leadership competency and telecentre outcomes. (1) Individual characteristics comprised gender, age, level of education, computer skill and innovativeness. Computer skill measured by the 11items scale developed by Carroll Community College (2010). Respondents should indicate their level of computer skill on a 5-point ordinal scale (1= Uncomfortable, $2=$ Somewhat uncomfortable, 3 = Somewhat comfortable, 4 = Comfortable, 5 = Very comfortable). To measure innovativeness the adapted version of scale developed by Madlock (2009) was used. In the present study, 11 items of 12 items of Madlock (2009) scale with 96 Cronbach's alpha was used. 5-point Likert-type response format ( $1=$ Strongly Disagree to $5=$ Strongly Agree) was used here. (2) Information characteristics scale developed based on literature review especially model of instruments tested by Whyte (2000) for assessing community telecentres. This scale consist of 9 items referred to access to local content and relevant content to community needs variable using 5 point Likert-type response format ( $1=$ Strongly Disagree to 5 = Strongly Agree). (3) Telecentre characteristics variables consist of location, infrastructure and type and quality of telecentre services. This scale established through reviewing the literature. Telecentre characteristics measurement scale modified based on the model of instruments tested by Whyte (2000) for assessing community telecentres guideline for researchers. Some items (items; 10, 11, 12 and 13) were used developed by Prado (2009) in study adoption of information and communication technologies at community technology centers. And items 4, 9, 14, 15, 16 and 17 developed by Akbulut et al. (2007) based on construct validation of ICT indicators measurement scale (ICTIMS). Also, items 18 and 19 developed by Siti et al. (2008). The measurement scale in this part consist of 18 items including; telecentre location (3 items including items; 1,3 and 13), telecentre infrastructure ( 7 items including items; 2, 4, 9, 11, 14, 17 and 18) and type and quality of telecentre services ( 8 items including items; 5, 6, 7, 8, 10, 12, 15 and 16). A 5 -point ordinal scale response format $(0=$ Not at all, 1 = Very little, 2 = Somewhat, $3=$ Quite a bit, $4=$ A lot) was used. (4) Leadership competency scale was established through reviewing the literature such as Burke (2002); Ladewig and Rohs (2000) and Mancini and Marek (2004). Leadership competency scale was consist of 14 items and a 5 ordinal scale response format ( $1=$ very poor, $2=$ Poor, $3=$ Moderate, $4=$ Good, $5=$ Very good) was used. (5) To measure telecentre outcomes the scale developed by Porenza et al. (2001) and used by Zulkefli and Sulaiman (2009) was imployed. The adopted measurement scales consist of 13 items modified and used to measure the three aspects of telecentre outcomes variable, namely participant needs met, empowering individuals and providing better economic condition. A 5 point Likerttype response format $(1=$ Strongly Disagree to $5=$ Strongly Agree) was used.

Validity and reliability: To determine construct validity of instrument the first-order CFA was carried out (Fig. 1 and Table 4). A pilot test was carried out in state of Selangor (Serdang district) and the data were collected from two telecenters (namely, MID Kapar and PID Sg Pelek) among 45 telecentre users to determine the reliability of instrument before the actual data 
collection. The reliability coefficient more than 0.70 for the all scales, indicating acceptable level of study instruments scales in term of reliability and exceeding the recommended alpha value (0.70) (Hair et al., 2010).

Analyses: SPSS and AMOS software were used to run the descriptive and inferential statistics analyses. Descriptive statistics were performed to summarize the responses to all independent and dependent variables. For this purpose percentage, means and standard deviations were employed. The Structural Equation Modeling (SEM) was employed as inferential statistics to test hypothesizes of the study.

\section{RESULTS}

Based on the results presented in Table 1, more than one-half $(52.8 \%)$ of the respondents were female and $47.2 \%$ were male. With respect to respondents' educational qualification, majority $(72.5 \%)$ of them were below a diploma. Near to one-half $(48.9 \%)$ of respondents had SPM (Malaysian Certificate of Education) and only $16.9 \%$ of the respondents had diploma. Out of 360 respondents, the majority (86.9\%) were in the younger age group (below 36 years old) and the average of respondent age was 25 years (Table 1).

Table 1: Distribution of respondents by gender, level of education and age $(n=360)$

\begin{tabular}{lrc}
\hline Variables & Frequency & Percentage \\
\hline Gender & 170 & \\
Male & 190 & 47.2 \\
Female & 1 & 52.8 \\
$\begin{array}{l}\text { Educational qualification } \\
\text { Never been to school }\end{array}$ & 7 & .3 \\
Primary school & 24 & 1.9 \\
Lower Malaysian & & 6.7 \\
certificates (PMR) & 176 & \\
Malaysian education & & 48.9 \\
certificates (SPM) & 53 & \\
Higher Malaysian & & 14.7 \\
education certificates (STPM) & 61 & 16.9 \\
Diploma & 37 & 10.3 \\
Bachelor degree (Ijazah) & 1 & .3 \\
Master/PhD & & \\
Age & 238 & 66.1 \\
16-25 & 75 & 20.8 \\
26-35 & 27 & 7.5 \\
36-45 & 20 & 5.6 \\
46 and above & &
\end{tabular}

Table 2: Level of perceived telecentre outcomes $(n=360)$

\begin{tabular}{lrrll}
\hline Level & Frequency & $\%$ & Mean & SD \\
\hline & & & 4.09 & 0.64 \\
Low (1-2.33) & & & & \\
Moderate (2.34-3.66) & 1 & 0.3 & & \\
High (3.67-5) & 86 & 23.9 & & \\
& 273 & 75.8 & & \\
\hline
\end{tabular}

Mean summated score for telecentre outcome was computed from a total of 7 items confirmed by CFA model. Based on the computed mean summated telecentre outcome score, telecentre outcome was grouped in three levels, namely low, moderate and high. The findings as showed that the majority of the respondents $(75.8 \%)$ perceived high average total score for telecentre outcomes, $23.9 \%$ scored moderate and only .3\% scored low. The overall mean score of telecentre outcomes is 4.09 , which is extremely higher than 3, (the mid-point between lowest possible average score (1) and the highest possible average score (5). The data indicated that the telecentres were success in achieved to outcomes which are the first aimed of produced them to rural community (Table 2).

The measurement model of study: Before evaluating the fit of structural model, it was necessary to define a measurement model to verify the construct validity of each research instrument which comprised individual items. For this purpose, CFA was carried out to assess model fit and construct validity based on the adequacy of factor loadings. In addition, the reliability (internal consistency) of each constructs was assessed using Cronbach's alpha (Table 4).

Based on the GOF indices as in Table 3, measurement model test reveals a relatively good fit between the proposed measurement model and the data. The results of assess the measurement model indicated that the data fit the model: $\chi^{2}(909)=1680.773, \mathrm{p}=$ $0.000 \chi^{2} / \mathrm{DF}=1.849 ; \mathrm{CFI}=0.908, \mathrm{IFI}=0.909, \mathrm{TLI}=$ 0.900, RMSEA $=0.049$.

The CFI, IFI and TLI significantly exceed the minimum cutoff value (0.9). In addition, the RMSEA was 0.049 , which fall between the recommended range of acceptability (between 0.03 and 0.08) (Hair et al., 2010). Thus shows that measurement model has a good fit with the data.

The construct validity of the instrument was also verified in this study, in that all the items had high standardized factor loading on their underlying constructs (values ranged from 0.51-0.89), were all significant at 0.001 (Table 3).

The measurement reliability was assessed using Cronbach's alpha. The alpha values for eight constructs ranged between 0.71-0.89. As shown in the Table 3, each construct achieved the minimum requirement of 0.7 , ensuring adequate internal consistency. 
The result of assessment of univariate normality in measurement model based on skew and kurtosis criteria within the range of $+/-2.0$ reveals no item to be nonnormal. Skewness were ranged from - 1.25 to -.224 and kurtosis ranged from 1.92 to -.820 .

The results of correlation estimates between the constructs in measurement model revealed no problems of multicollinearity between the constructs. The correlation estimates between the constructs ranged between $0.26-0.83$.

The individual characteristic construct comprised two dimensions, namely computer skill and innovativeness. The initial computer skill and innovativeness dimensions were made up of 11 items each. Through the use of first-order CFA and after eliminating items with standardized regression coefficients (factor loading) less than 0.50 , only seven items remained for computer skill and six items for innovativeness dimension (Table 3).

The initial construct of telecentre characteristics comprised 18 items that measured suitability of telecentre location (3 items), infrastructure ( 7 items) and type and quality of telecentre services ( 8 items). The results of CFA model as depicted in the Fig. 1 showed that only 10 items met the minimum of standardized regression coefficients of 0.50 .

The information characteristic construct were made up of 9 items comprised two dimensions, namely access to local content (4 items) and relevant content to community needs (5 items). Through the use of first-order CFA and after eliminating one items with standardized regression coefficients (factor loading) less than 0.50, eight items remained.

The initial construct of leadership competency was consisted of 12 items. Through the use of first-order CFA and after eliminating items with standardized regression coefficients (factor loading) less than 0.50 , only nine items remained.

The initial telecentre outcome construct made up of 12 items. The results of CFA model showed that eight items met the minimum of standardized regression coefficients of 0.50 .

Table 3: The construct validity and composite reliability results of the measurement model

Constructs and indicators (items)

Standardized factor

[Individual characteristics]

Computer skill

Identify the make and model of your computer (Item 2)

Switching off computers correctly (Item 4)

Connecting to the Iternet (Item 6)

Create a bookmark or save a favorite web page (Item 7)

Use a search engine to locate information on the Internet (Item 8)

Communicating (E-Mail, Messenger, Chatting) (Item 9)

Working with Word Processing (Microsoft Word) (Item 10)

Innovativeness

My peer often ask me for advice or information(Item 1)

I enjoy trying new ideas (Item 2)

I am generally cautious about accepting and trying new ideas (Item 3)

I frequently improvise methods for solving a problem when an answer

is not apparent (Item 4)

I consider myself to be creative and innovative in my thinking and

behavior, especially in terms of using computers (Item 7)

I tend to feel that the old way of living and doing things is the best way (Item 9)

[Telecentre characteristics]

Location

The Location and access of the Telecentres are convenient for me (Item 1)

distance for the community (Item 3)

The telecentres are located within an appropriate geographical

Telecentre is too far from my home (Item 13)

Type and Quality of services

I am satisfied with the quality of Telecentre services

(e.g. Telephones, photocopier, fax, computers, Internet connections) (Item7)

The Telecentre is always open at a time when I can visit (Item 10)

Computers are fast enough to use for doing activities (Item 14)

The Telecentres do provide opportunities for further improvement of my

knowledge and skills in using computers (Item 16) loading

$(>0.5)$

Reliability $(>0.7)$

0.88

0.65

0.67

0.75

0.69

0.71

0.81

0.81
0.76

0.8

0.82

0.71

0.71

0.52

0.51

0.66

0.71

0.68

0.56

0.74

0.62

0.6

0.76

0.71 
Am. J. Applied Sci., 8 (6): 617-627, 2011

Table 3: Continue

\section{Infrastructure}

The facilities and equipment provided by Telecentre are satisfactory (Item 2)

0.71

The interior condusiveness of the telecentres are satisfactory (Item 4)

The speed of the Internet at the telecentres is appropriate (Item 9)

[Information characteristics]

Access to local content

Information needs of local users are available in telecentres (Item 1)

Local information through local web pages is available adequately (Item 3)

The information provided by Telecentre is locally useful and valued information (Item 5)

The information available at the Telecentres are only available in English language (Item 6)

Relevant content to needs

The information provided by Telecentres is Up-to-date (e.g. information

on markets, prices and so on) (Item 2)

The Telecentre information is more relevant to the local needs (Item 4)

I found the information provided by the Telecentres is easy to use (Item 7)

Telecentre information is comfortable with my needs (Item 8)

[Leadership competency]

Ability to identify problems of Telecentre services (Item 1)

Aware of what is necessary to solve the problem about Telecentre services (Item 3)

Ability to assist users with regards to Telecentre services offered (Item 5)

Provide clear and well-organized instructions to users and staff (Item 8)

Possess good listening skills when interacting with the users (Item 9)

Ability to communicate complex issues in understandable terms (Item 10)

Possess adequate social skills (Item 11)

Create environment where leaders and people in rural community are

approachable and are open to new ideas (Item 12)

[Telecentre outcomes]

Improve work related skills (Item 1)

Find employment/ job creation (Item 3)

Save time in terms of engaging in online transactions

Table 3: Continues

Increase earnings from farms or businesses (Item 5)

More confident and knowledgeable in making online purchases (Item 9)

Better informed (Item 10)

Find friends, make new friends or maintain existing friendship (Item 11)

Encourage information sharing (Item 12)

0.75

0.6

0.55

0.61

0.82

0.77

79

0.77

0.89

0.78

0.84

0.69

0.74

0.72

0.73

0.77

0.78

0.76

0.74

0.73

0.68

0.66

0.71

0.71

0.74

0.72

0.79

Table 4: Unstandardized and standardized regression weights in the hypothesized path model

\begin{tabular}{|c|c|c|c|c|c|}
\hline Hypothesized relationships & $\begin{array}{l}\text { Unstandardized } \\
\text { regression weights } \\
\text { estimate B }\end{array}$ & S.E. & $\begin{array}{l}\text { Standardized } \\
\text { regression } \\
\text { beta }\end{array}$ & C.R. & $\mathrm{P}$ \\
\hline Individual characteristics $\rightarrow$ Telecentre outcomes & 0.235 & 0.071 & 0.218 & 3.325 & 0.000 \\
\hline Telecentre characteristics $\rightarrow$ Telecentre outcomes & 0.292 & 0.078 & 0.239 & 3.728 & 0.000 \\
\hline Information characteristics $\rightarrow$ Telecentre outcomes & 0.201 & 0.045 & 0.273 & 4.433 & 0.000 \\
\hline Leadership competency $\rightarrow$ Telecentre outcomes & 0.221 & 0.057 & 0.234 & 3.908 & 0.000 \\
\hline
\end{tabular}

Relations between selected independent variables and telecentre outcomes: The SEM was used with the aim of determining the contribution of each set of independent variable entered in the equation in relation to the dependent variable. The results are presented in Fig. 1 and Table 4. The results of assessing the structural model fits indicated that the data fit the model with; $\chi^{2}(220)=565.211, \mathrm{p}=0.000$, $\chi^{2} / \mathrm{DF}=2.569 ; \mathrm{GFI}=0.875, \mathrm{CFI}=0.920, \mathrm{TLI}=0.908$, IFI $=0.921$, RMSEA $=0.066$. The Goodness-of-fit indices of structure model showed that the CFI, TLI and IFI significantly pass its cutoff value (0.9). In addition, the RMSEA was 0.066 , which fall between the recommended range of acceptability (between 0.03 and 0.08 ).
The results of SEM analyses between the independent/ exogenous variables and telecentres outcomes were as follows:

H1: There is a significant relationship between individual characteristics and perceive telecentre outcomes

Individual characteristics: The result of the structural model, according to Table 4, indicated that the individual characteristics latent construct including two indicators of computer skill and innovativeness had significant contribution towards the prediction of telecentre outcomes. The standardized path coefficient showed that the data were consistent with the 
hypothesis by indicating a significant relationship ( $\beta=$ 0.218 , C.R. $=3.325, p=0.000$ ) between the individual characteristic and telecentre outcomes. Therefore, H1was supported:

$\mathrm{H} 2$ : There is a significant relationship between telecentre characteristics and perceive telecentre outcomes

Telecentre characteristics: As depicted in Fig. 1 and Table 4, the telecentre characteristic latent construct consist of three indicators of telecentre location, telecentre infrastructure and type and quality of telecentre services, was found to have significant relationship with telecentre out comes $(\beta=.239$, C.R. $=$ $3.728, \mathrm{p}=0.000)$. As depicted in Fig. 1, type and quality of telecentre services indicated by the highest standardized coefficient .88 , followed by telecentre infrastructure indicator with the standardized coefficient 0.71. Thus, based on structural model results, the hypothesized significant relationship between the telecentre characteristics and perceived telecentre outcomes was supported.
H3: There is a significant relationship between information characteristics and perceive telecentre outcomes.

Information characteristics: Based on structural model the information characteristic latent construct consist of two indicators of access to local content and relevant content to respondent needs, was found to have significant relationship with social sustainability of telecentre $(\beta=0.273$, C.R. $=4.433$, Sig $=0.000)$. The information characteristics were indicated by relevant content to respondent needs with the highest standardized coefficient 0.98 . Thus, the third hypothesis also was supported.

H4: There is a significant relationship between leadership competency and perceive telecentre outcomes.

Leadership competency: According to the results as showed in Fig. 1 and Table 4, there is a significant relationship between leadership competency latent construct and telecentres outcome $(\beta=0.234$, C.R. $=$ $3.908, \mathrm{P}=0.000$ ). Therefore, $\mathrm{H} 3$ was supported.

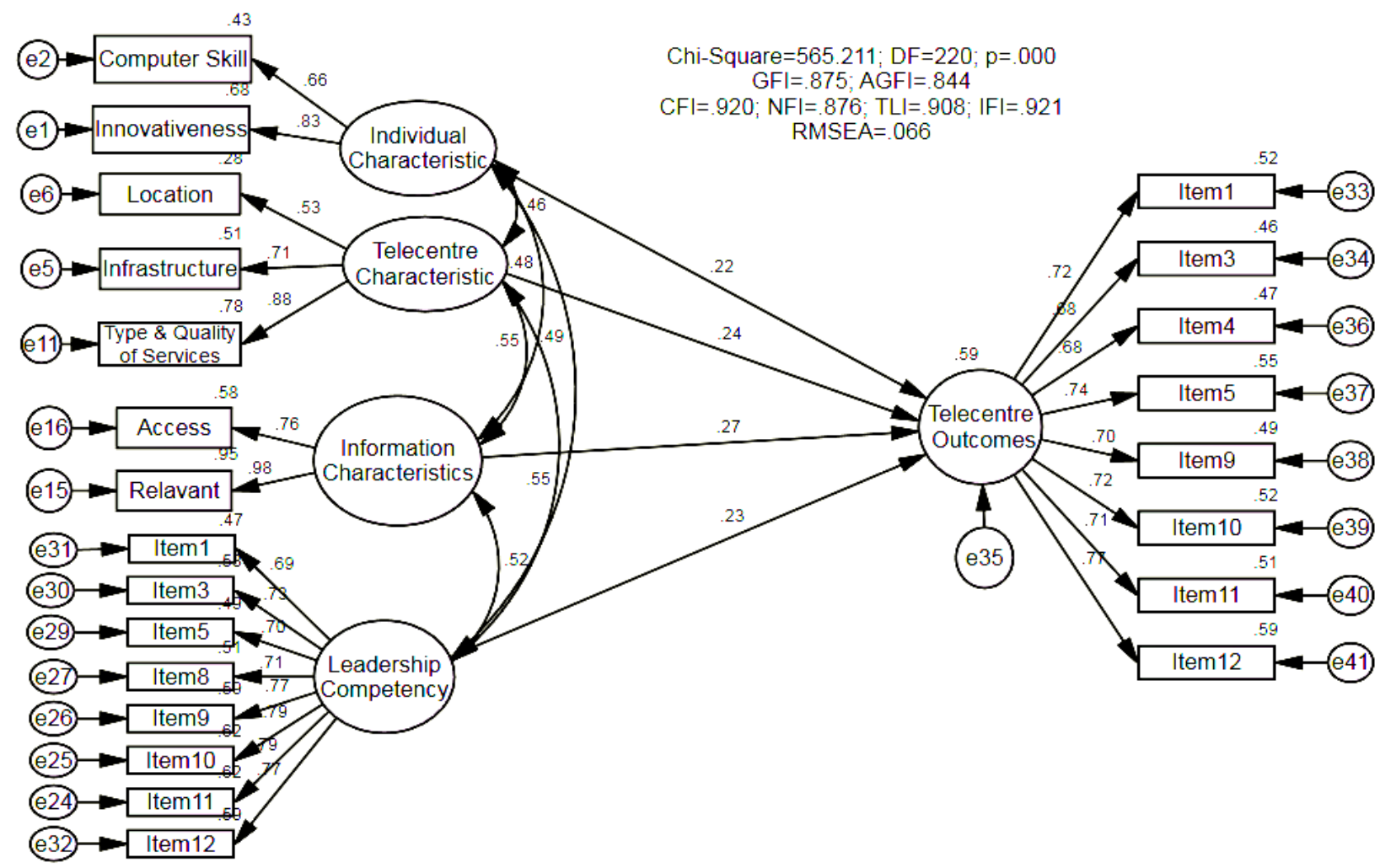

Figure 1: The structural model of the study 


\section{DISCUSION}

The finding of the current study about computer skill (under individual latent construct) is consistent with Mansell and Wahen (1998) finding who argued availability of appropriate skill is central to the successful development of ICT project. Also, this finding is consistent with Proenza et al. (2001) ideas who found a successful telecentre experience requires familiarity with computers. In this case Islam and Hasan (2009) stated that the rural people with low level of skills about computer use and internet navigation feel embarrassed to go to telecentres. Thus, one possible argued is that the low level of computer skill could influence perceived telecentre outcomes. These findings of the current study about innovativeness showed that the innovator people better perceived the telecentre outcome which is in line with the Rogers (2003) point of view about the innovators.

The results of current study about the significant relationship between telecentre characteristic indicators is consistent with previous studies such as Bailey and Ngwenyama (2009) finding who argued that the location is a key factor in telecentre success. Also this finding supports previous research by Kumar and Best (2006) which claimed that spatial location and operation of the telecentres can significantly improve their social diffusion. Although, these results differ from some before studies which found the location of the project is not a barrier to the development and success of ICT projects in rural areas (Jusang et al., 2009). This study produced results about the effect of telecentre infrastructure on telecentre outcomes which corroborate the findings of a great deal of the previous work in this area (for instance: Best and Maclay, 2002; Best et al., 2009; Jusang et al., 2009; Jauernig, 2003; Meddie, 2006; Etta and Parvyn-Wamahiu, 2003). This study produced results about the effect of telecentre type and quality of telecentre on telecentres success and outcomes, supports previous research Zahurin et al. (2009). Norizan and Jalaluddin (2008) in another study about telecentres in Malaysia indicated that the telecentres to be success and achieve to expected outcomes they must be well provided with the sufficient number of hardware and services for the community.

This finding of the current study about the significant contribution of information characteristics is in agreement with Best et al. (2009) findings. Furthermore, this finding supports previous research by Pade et al. (2009) which recognized the building on local information and knowledge systems as critical factor for success and access to main objective of rural ICT project which is telecentre outcomes. Thus, accessibility of the local content are the matter that needs to be taken into consideration in the development of digital content is especially for people in rural and remote areas (Jamaluddin et al., 2009). These findings of the current study in relation to the effect of relevant provided content by telecentres on the outcomes of them, are consistent with Pade et al. (2009) which based on study the rural ICT projects (The Dwesa Case Study in South Africa) recognized that, focusing on local/demand driven needs and facilitating local content development are the critical success factors. In addition, this finding is in agreement with Siti et al. (2008) finding in Malaysia which found the main reason for do not participate of respondents in ICT projects because the activities undertaken in the ICT project is not in accordance with their needs. Thus, the ICT project to be meaningful and there must be locally relevant content to community needs.

Finally the result of the current study about the significant relationship between the leadership competency and telecentre outcomes confirmed the Mancini and Marek (2004) findings who stated leadership and staffing are likely the primary "linchpins" in program success and sustainability.

\section{CONCLUSION}

The ICT project is the key to access the international economic progress, supporting rural community development and procedures (Bozinis, 2007). Therefore it is essential to look at the predicting factors of its outcome. Based on the structural equation model analyses the proposed predictor variables of this study in hypothesized path model, explained 59\% of variance of telecentres outcomes. Thus the study variables explained more than half of the variance in the telecentres outcomes.

The information characteristics with highest standardized regression weight $(\beta=0.27)$ had a highest significant contribution among investigated factors, toward predicting the perceived telecentres outcomes. In this regards, efforts must be made to improve service quality and provide relevant content to respondent needs in local language. Access to local and relevant content can play a critical role in stimulating the users in rural community to have a continuous connection with telecentres and later achieving desire outcome. 
The significant relationships between the predictor variables and perceived telecentre outcomes shows that; availability of appropriate skill and high level of innovativeness as determinant of individual characteristics are fundamental toward successful development and perceived better outcomes of ICT project in rural community. Also, it can be concluded that suitability of telecentre location, appropriateness of infrastructure and adequate type and quality of telecentre services influence the perceived outcomes of telecentres in rural community; and finally taking into consideration the leadership competency to achieved telecentres outcomes is crucial. Telecentres with a team possessing strong leadership competency have a better chance to achieve desire outcome such as meeting the community need, empowering individual and providing better economic situation even after the termination of support from the government or donor agenesis.

The implication of findings could be discussed from donor agencies and governments perspectives involved with development-oriented telecentres to consider the critical factors. The results of such a consideration are beneficial to various groups that are directly or indirectly involved in the planning, execution, evaluation and usage of ICT projects to enhance greater telecentres achievement and outcomes for rural community.

\section{REFERENCES}

Akbulut, Y., Kesim, M. and Odabasi, F., 2007. Construct validation of ICT indicators measurement scale (ICTIMS). Int. J. Educ. Develop., 3.

Ali, M. and S. Bailur, 2007. The challenge of sustainabilityin ICT4D- in bricolage the answer. Proceedings of the Paper Presented at the 9th International Conference on Social Implications of Computers in Developing Countries, São Paulo, Brazil.

Bailey, A., 2009. Issuses affecting the social sustainability of telecentres in developing contexts. Afield study of sixteen telecentres in Jumaica. Elect. J. Inform. Syst. Dev. Countries, 4: 1-18.

Bailey, A. and Ngwenyama, O. (2009). Social ties, literacy, location and the perception of economic opportunity: Factors influencing telecentre success in a development context. Paper presented at the Proceedings of the 42nd Annual Hawaii International Conference on System Sciences HICSS, $\quad$ pp: 1-11. 2009, DOI:10.1109/HICSS.2009.398
Best, M. L., Thakur, D. and Kolko, B. E. (2009). The contribution of user-based subsidies to the impact and sustainability of telecenters-the eCenter project in Kyrgyzstan1. Paper presented at the Information and Communication Technologies and Development (ICTD), 2009 International Conference on, 17-19 April 2009, pp. 192 - 200, doi:10.1109/ICTD.2009.5426709

Bozinis, A. I., 2007. International Economic Relations and Information Communication Technologies (ICT) Use: Economic Globalization via Economic Digitalization American Journal of Applied Sciences 4(4), 188-191.

Burke, T.B., 2002. Defining competency and reviewing factors that may impact knowledge. Perceived importance and use of competencies in the $4-\mathrm{H}$ professional's job (doctoral dissertation). North Carolina University Raleigh.

Colle, R.D., 2004. ICTs, Telecenters and Community Development. USA Department of Communication Cornell University, New York, pp. 23.

Etta, F. and Parvyn-Wamahiu, S. (2003). Information and Communication Technologies for Development in Africa.The Experience with Community Telecenters (Vol. 2). Ottawa: the International Development Research Centre (IDRC), ISBN: 9782869781153, pp: 228.

Farr, P. and F. Papandrea, 2004. Achieving sustainable community online access centers. Proceedings of the Paper Presented at the International Telecommunications Society, 15th ITS Biennial Conference, September 5-7, 2004 Berlin, Germany.

Farr, P. and Papandrea, F., 2006. Sustainability of Community Online Access Centres. In: Governance of Communication Networks, B. Preissl and J. Müller (Eds.), Physica-Verlag HD, pp: 165-185. ISBN: 978-3-7908-1746-1, doi: 10.1007/3-7908-1746-5_10

Gómez, R., Hunt, P. and Lamoureux, E. (1999). Telecentre Evaluation and Research: a global perspective. In I. Ricardo Gómez and Patrik Hunt (Ed.), 1. Ottawa, Canada: International Development Research Centre, pp: 312.

Harris, R. W., 2001. Telecentres in rural Asia: Towards a success model. Paper presented at the Information Technology and Communications for Development, Kathmandu , Nepal, 29-30 November 2001.

Hair, J.F., W.C. Black, B.J. Babin and R.E. Anderson, 2010. Multivariate Data Analysis. 7th Edn., USA, New Jersey 07458: Prentice Hall, pp.816, ISBN: 0138132631 
Harris, K. Yogeesvaran and L.W.Y. Lee, 2007. Telecentres for National e-Inclusion in Malaysia. http://i4donline.net/ATF/2007/fullpapers/RogerATF07ABS113.pdf

Islam, M.S. and M.N. Hasan, 2009. Multipurpose community telecentres in Bangladesh: Problems and prospects. Elect. Library, 3: 537-553.

Jamaluddin, A., A.R. Norizan, A.M. Jalaluddin, M.N. Nor Fariza and A. Zaini et al., 2009. Community broadband: Towards education for all. Paper presented at the Proceedings of the 8th WSEAS International Conference on Education and Educational Technology (EDU'09). http://www.wseas.us/conferences/2009/genova/ed/

Jauernig, C., 2003. Review of Telecenter Sustainability Criteria for the Establishment of Sustainable Rural Business Resource Centers for SMEs in Developing Countries United Nations Industrial Development Organization (UNIDO), Vienna.

Jusang, B.B., A. H. Musa, I. Narimah and Z.O. Siti, 2009. ICT Projects in Rural Development: Recommendations of the K-Community Development Generating, Media and agricultural development; efforts to considerate the rural communities, D. Bahaman, (Ed.)., Serdang, Selangor: UPM, pp: 67-75.

Kumar, R. and Best, M., 2006. Social impact and diffusion of telecentre use: A study from the Sustainable Access in Rural India project. Journal of Community Informatics, 2(3). Retrieved July 25, 2010, from http://mikeb.inta.gatech.edu/uploads/ papers/328-1701-1-PB-1.doc

Ladewig, H. and F.R. Rohs, 2000. Southen extension leadership development: Leadership development for a learning organization. J. Extension, 38.

Lee, J.W., 2001. Education for technology readiness: Prospects for developing countries. J. Hum. Dev., 1: 115-151.

Madlock, P. E., 2009. The development of technological managementmodel: a conceptualization of computer technology in the workplace Doctor of Philosophy West Virginia University.

Mancini, J.A. and L.I. Marek, 2004. Sustaining community-based programs for families: Conceptualization and measurement. Family Relations, 4: 339-347.

Mansell, R. and Wahen, U. (1998). Knowledge Societies: Information Technology for Sustainable Development (1 ed.). United States: Oxford University Press, pp. 323, ISBN: 0198294107.
Musa, A. h. and Hasim, M. S., 2008. my Malaysia. In F. Libero (Ed.), Digital Review of Asia pacific 2007-2008 (pp. 196-203). India Pvt Ltd: SAGE

Nor Iadah, Y., A.M.Y. Shafiz, M.A. Zahurin, H.I. Huda, M.K. Khairudin and M. D. Zulkhairi, et al. 2010. The influence of community characteristics towards telecentres success. Com. Infor. Sci. 2, P116.

Norizan, A.R. and A.M. Jalaluddin, 2008. Bridging Digital Divide in Malaysia: Cyber Learning for the Marginalized Community.

Pade, C.I., B. Mallinson and D. Sewry, 2009. An Exploration of the Critical Success Factors for the Sustainability of Rural ICT Projects-The Dwesa Case Study Information Systems Development pp: $1-14$.

Prado, P. , 2009. Bridging digital poverty: Adoption of information and communication technologies at community technology centers in the Dominican Republic. Ph.D., University of Miami, United States -- Florida.

Proenza, F.J., 2001. Telecenter sustainability: Myths and opportunities. J. Dev. Commun., 2: 94-109.

Proenza, F. J., Buch, R. B. and Montero, G., 2001. Telecenters for socioeconomic and rural development in Latin America and the Caribbean. From Washington, DC, Inter-American Development Bank http://www.iadb.org/sds/itdev/telecenters/index.htm

Rahman, M. A., M.U. Mahfuz, K.M. Ahmed and R.M.A.P. Rajatheva. 2005. ICT based Sustainable Rural Business Opportunities in Developing Countries: A Wireless-Networked RCP-RAP Approach. Am. J. Applied Sci, 2, 1256-1260. doi: 10.3844/ajassp.2005.1256.1260

Rahman, M.Z. and A.S.K. Pathan, 2010. A case study: establishing redundant access networks in the telecommunication sector of a developing country. Int. J. Inform. Tech. Commun. Countries., 1: 108-126.

Rogers, E. M. (2003). Diffusion of Innovations. 5th Edn., NY 10020, New York, pp: 512.

Samah, B. A., Shaffril, H. A. M., Hassan, M. A. and D'Silva, J. L., 2011. Can technology acceptance model be applied on the rural setting: the case of village development and security committee in Malaysia. J. Soc. Sci., 7: 113-119. DOI: 10.3844/jssp.2011.113.119

Siti, Z.O., A.H. Musa, I. Narimah and B. Jusang, 2008. Faktor-faktor kejayaan dan kegagalan projek ICT di luar bandar [Success and failure factors of rural ICT projects]. Pertanika J. Soc. Sci. Hum., 2: 173-186. 
Slaymaker, R.C.T., 2002. ICTs and Rural Development: Review of the Literature, Current Interventions and Opportunities for Action (No. Working Paper 192 Results of ODI research presented in preliminary form for discussion and critical comment). London, SE1 7JD, UK.

Supyan, H., A.R. Norizan and M.N. Nor Fariza, 2009. Planning and implementation of educational programs at e-community centers in a rural area in Malaysia. Paper presented at the Proceedings of the 8th WSEAS International Conference on EActivities and Information Security and Privacy.

UNESCAP. 2006. Guid book on developing community-centers in rural areas: Based on the Malaysian experience, New York.
Whyte, A., 2000. Assessing Community Telecentres; Guidelines for Researchers (pp. 120). Retrieved from http://www.idrc.org/en/ev-9415-201-1DO TOPIC.html.

Zahurin, M. A., Huda, H. I., Khairudin, M. K., Nor Iadah, Y., Affendi, M. Y. S. and Zulkhairi, M. D. (2009). Management Practice Sustaining Telecentres. Paper presented at the Kebangsaan EKomuniti 2009 Merapatkan Jurang Digital: Masyarakat Berpengetahuan, Model Malaysia, Pusat Kajian E-Komuniti, FSSK, UKM, Hotel PNB Darby Park, Kuala Lumpur, 18 - 19 Mac, pp.273-280.

Zulkefli, I. and A. Sulaiman, 2009. The influence of Malaysian telecenters on community building. Elect. J. e-Gover., 1: 77-86. Available from www.ejeg.com 